\title{
A ESTRUTURAÇÃO DA VIOLÊNCIA CONTRA A PESSOA IDOSA: UMA REVISÃO SISTEMÁTICA
}

Italo Marcucci; Universidade de Rio Verde (UNIRV), Goianésia, GO; italomarcucci@hotmail.com Gabriel Monteiro de Castro; Universidade de Rio Verde (UNIRV), Goianésia, GO; gabrielcasteiro@gmail.com João Lucas Rocha Silva; Universidade de Rio Verde (UNIRV), Goianésia, GO; joaolucasrocha.2014@gmail.com Pedro Henrique Santos Lima; Universidade de Rio Verde (UNIRV), Goianésia, GO; pedrohsI64@gmail.com Vicente Pereira de Carvalho Neto; Universidade de Rio Verde (UNIRV), Aparecida, GO; vicente25carvalho@gmail.com

Victoria Elias de Freitas Honorato; Universidade de Rio Verde (UNIRV), Aparecida, GO; vick_freitas2@hotmail.com Weberton Dorásio Sobrinho; Universidade de Rio Verde (UNIRV), Goianésia, GO; dorasioweberton@gmail.com Danyelly Rodrigues Machado Azevedo; Universidade de Rio Verde (UNIRV), Goianésia, GO; danyelly.rodrigues@unirv.edu.br

\section{RESUMO}

Introdução: A violência que se estrutura no espaço intrafamiliar é muito delicada, sendo difícil penetrar no silêncio das famílias dos idosos violentados. Somando-se a delicadeza do tema à vulnerabilidade dos idosos à violência, nota-se que as desvantagens desse segmento social são inúmeras, principalmente devido ao processo de envelhecimento que tende a debilitar e reduzir as funções cognitivas e defesas do organismo. Assim, deve-se estender os olhos para além da violência física, pois se trata de uma gama maior. Objetivo: Analisar a construção do cenário da violência contra a pessoa idosa e identificar os principais fatores que ajudam para esse ato. Métodos: Trata-se de um resumo expandido com análise de coleta de dados nas plataformas de pesquisa SciELO e Agência Brasil através dos descritores: "Agressão; Fragilidade; Maus-Tratos ao Idoso; Violência Doméstica". Resultados: Foram selecionados 7 artigos para a leitura completa dos autores, e os estudos apontaram que a faixa etária, predominante, das vítimas varia entre 76 e 80 anos e entre 66 e 70 anos. As vítimas se declaram, por ordem crescente, brancas, pardas, pretas, amarelas e indígenas. Ademais, foi possível identificar que os principais fatores que colaboram para tal ato contra a pessoa idosa são o medo, a perda da mobilidade, a função cognitiva reduzida e a insegurança. Conclusão: Portanto, as estatísticas pertinentes à violência contra o idoso se estruturam devido ao oportunismo dos agressores frente a suscetibilidade, principalmente o sexo feminino, a vulnerabilidade de suas vítimas e ao silêncio daqueles que são violentados pelas pessoas que amam.

Palavras-chave: Agressão; Maus tratos ao idoso; Violência doméstica. 